\title{
Hypersensitivity and jaundice due to azathioprine
}

\author{
M. DAVIS \\ M.D., M.R.C.P.
}

A. L. W. F. EDDLESTON
D.M., F.R.C.P.

\author{
ROGER WILLIAMS \\ M.D., F.R.C.P.
}

The Liver Unit, King's College Hospital and Medical School, London, S.E.5

\begin{abstract}
Summary
A patient is described who suffered hypersensitivity reactions (anorexia, nausea and vomiting) as well as cholestatic jaundice from therapy with azathioprine. Evidence is given that the 2 reactions were mediated by different portions of the azathioprine molecule.
\end{abstract}

\section{Introduction}

Azathioprine is a widely used immunosuppressive agent, with few adverse effects apart from bone marrow suppression which occurs with higher doses (Calabresi and Parks, 1970). Occasional hypersensitivity reactions with skin rashes, pyrexia and abdominal pain have, however, been reported (Willoughby et al., 1971; King et al., 1972), and cholestatic jaundice, possibly due to a direct toxic effect of the drug, has also been observed in patients receiving azathioprine for the treatment of leukaemia and following renal transplantation (Davis and Williams, 1977). In this communication the authors report a patient in whom both types of adverse effects were experienced, and present evidence that the 2 reactions were mediated by different portions of the azathioprine molecule.

\section{Case report}

Chronic active hepatitis was diagnosed, on the basis of liver biopsy findings, in a 55-year-old woman. She was treated initially with azathioprine $(100 \mathrm{mg}$ daily), and 3 weeks later prednisone (15 $\mathrm{mg}$ daily) was added. Four weeks after starting azathioprine she developed anorexia, nausea and vomiting and the drug was withdrawn with prompt regression of symptoms.

Some 18 months later, prednisone was reduced to $12.5 \mathrm{mg}$ daily because of cushingoid side effects, and azathioprine reintroduced in a smaller dose $(25 \mathrm{mg}$ daily). Nausea and vomiting returned within 14 days. The serum bilirubin level rose from 57 to $380 \mu \mathrm{mol} / \mathrm{l}$ but aspartate aminotransferase (AST) and alkaline phosphatase were unchanged. Symptoms again remitted when azathioprine was discontinued.
Since this patient developed severe side effects on prednisone alone, whenever the dose was increased to a sufficient level to control the liver disease, it was decided to carry out, with the patient's consent, a o challenge test with azathioprine to establish that her symptoms were due to sensitivity to the drug $\rightarrow$ rather than to spontaneous fluctuation in her disease. $\mathrm{O}$ A single oral $(5 \mathrm{mg})$ dose of the drug was adminis- $\rightarrow$ tered and about one hr later the patient complained $\rightarrow$ of headache, nausea, and malaise, and then developed colicky abdominal pain, vomiting and pyrexia. $\vec{\bullet}$ Symptoms subsided over the next $24 \mathrm{hr}$. Liver fun 8 tion tests and leucocyte count remained unchangef but serum amylase rose from 180 i.u./1 (norma $<300$ i.u./l) to 650 i.u./litre $24 \mathrm{hr}$ later, levets returning to normal by the following day.

It was decided to try 6-mercaptopurine (6-MP) instead of azathioprine and, because of the close $\propto$ structural similarity between the two drugs, an $\overrightarrow{\overrightarrow{0}}$ initial single $(25 \mathrm{mg})$ dose was given. This produced $\frac{3}{3}$ no ill effects, and regular treatment $(25 \mathrm{mg}$ thrice $/ \bar{F}$ day) was started, with improvement in liver function? tests. Over the following 2 weeks, however, serum bilirubin levels rose from 18 to $480 \mu \mathrm{mol} / \mathrm{l}$, but levels of AST and alkaline phosphatase remained stable, and the patient had no symptoms similar to those experienced previously. 6-MP was withdrawn, and $ᄋ$ serum levels returned to normal over the following 2 weeks.

\section{Discussion}

The development of fever, headache and gastrointestinal symptoms after 4 weeks' treatment with azathioprine, with prompt recurrence on subsequent $N$ exposure to the drug, strongly suggests a hyper- $\mathbb{W}$ sensitivity reaction. Similar reactions have been? reported in patients receiving the drug for auto- 0 immune conditions (King et al., 1972; Adams, Gordon and Maxwell, 1967; Corley, Lessner and $\stackrel{\odot}{+}$ Larsen, 1966), and Crohn's disease (Willoughby 꿍 et al., 1971; Druckner and Jeejeebhoy, 1970; Brown

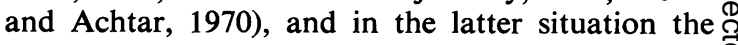


gastrointestinal symptoms may mimic a relapse of the disease. The present patient also developed acute pancreatitis, as evidenced by a rise in serum amylase, and this has also been reported as a rare complication of azathioprine therapy (Nogueira and Freedman, 1972). The failure of 6-MP to elicit a hypersensitivity response indicates that the imidazole side chain of the molecule was responsible for this effect, for azathioprine differs from 6-MP only in possessing this moiety (Calabresi and Parks, 1970) (Fig. 1). In vivo, cleavage of the 2 components occurs with liberation of free 6-MP.

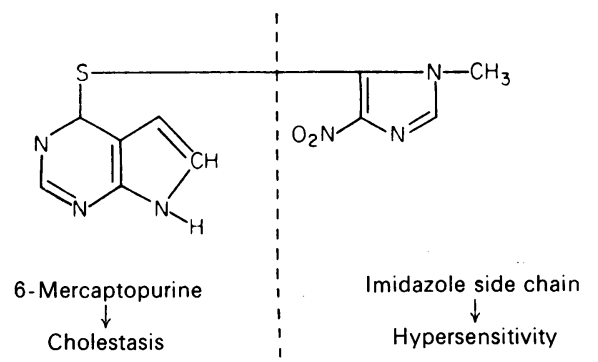

Fig. 1. Structure of azathioprine in relation to side effects of the drug.

In contrast, the jaundice would seem to be related to the 6-MP portion of the molecule, for it appeared both after 6-MP and azathioprine. Competition between the drug and bilirubin excretion seems the most likely mechanism in view of the lack of constitutional symptoms and the failure of AST or alkaline phosphatase to rise. This is in keeping with experimental studies in dogs showing a dose-related effect of the drug (McIlvanie and MacCarthy, 1959; Starzl et al., 1965), although hepatocellular necrosis has also been reported following both 6MP and azathioprine (Einhorn and Davidson, 1964; Sparberg, Simon and Del Greco, 1969). In man, jaundice is generally only seen when doses of azathioprine and 6-MP in excess of $2.5 \mathrm{mg} / \mathrm{kg} /$ day are given (Davis and Williams, 1977), but in the present patient this complication developed after a much lower dose. However, it is known that patients with liver disease are especially susceptible to hepatic side effects from these compounds (Mistilis and Blackburn, 1967) and the dose necessary to produce jaundice may thus be lower.

\section{References}

Adams, D.A., Gordon, A. \& Maxwell, M.H. (1967) Azathioprine treatment of immunological renal disease. Journal of the American Medical Association, 199, 459.

Brown, C.H. \& AchTAR, E. (1970) Azathioprine therapy for inflammatory bowel disease. A preliminary report. American Journal of Gastroenterology, 34, 363.

CAlabresi, P. \& PARKs, R.E. (1970) In: The Pharmacological Basis of Therapeutics. (Ed. by Goodman, L.S. \& Gilman, A.), p. 1371. Macmillan, London and Toronto.

Corley, C.C., Lessner, H.E. \& LARSEN, W.E. (1966) Azathioprine therapy of 'autoimmune diseases'. American Journal of Medicine, 41, 404.

Davis, M. \& Williams, R. (1977) Drugs and the liver. In: Textbook of Adverse Drug Reactions. (Ed. by Davies, D.S.). Oxford University Press.

DruCKNER, W.R. \& JeEJEebhoY, K.N. (1970) Azathioprine: an adjunct to surgical therapy of granulomatous enteritis. Annals of Surgery, 172, 618.

EINHORN, M. \& DAvidSON, I. (1964) Hepatoxicity of mercaptopurine. Journal of the American Medical Association, 188, 802.

King, J.O., LAver, M.C., Fairley, K.F. \& Amis, G.A. (1972) Sensitivity to azathioprine. Medical Journal of Australia, 2, 939.

McIlvanie, S.K. \& MacCarThy, J.D. (1959) Hepatitis in association with prolonged 6-mercaptopurine therapy. Blood, 14, 80.

Mistilis, S.P. \& BlackbuRn, C.R.B. (1967) The treatment of active chronic hepatitis with 6-mercaptopurine and azathioprine. Australian Annals of Medicine, 16, 305.

NogueirA, J.R. \& Freedman, M.A. (1972) Acute pancreatitis as a complication of Imuran therapy in regional enteritis. Gastroenterology, 62, 1040.

SparberG, M., Simon, N. \& Del Greco, F. (1969) Intrahepatic cholestasis due to azathioprine. Gastroenterology, $57,439$.

Starzl, T.E., Marchioro, T.L., Potter, K.A., TAylor, P.D., Favis, T.D., Herrman, T.J., Hlad, C.J. \& WadDELL, W.R. (1965) Factors determining short and long. term survival after orthotopic transplantation in the dogSurgery, 58, 131.

Willoughby, J.M.T., Kumar, P.J., Beckett, J. \& Dawson, A.M. (1971) Controlled trial of azathioprine in Crohn's disease. Lancet, ii, 944. 